\title{
The Auto Evaluation Method of Airline
}

\section{ZHANG Lin ${ }^{\text {a, }}{ }^{*}$, LIU Huayun and CHENG Weiming}

\author{
State Key Laboratory of Air Traffic Management System, the 28th Research Institute of China \\ Electronics Technology Group Corporation, Nanjing 210007, China \\ achen7225@msn.com, ${ }^{*}$ corresponding author
}

Keywords: airline evaluation; multi-objective decision-making; triangular fuzzy number; TOPSIS; gray system theory

\begin{abstract}
In order to evaluate the effectiveness of automatically generated attack airline from mission planning system. The evaluation model is put forward, which is the integration of fuzzy theory, the grey system theory and multi-objective decision method of TOPSIS (Technique for Order Preference by Similarity to an Ideal Solution) method. First the fuzzy theory is adopted to process the weights of airline evaluation index, using grey system theory to calculate the TOPSIS distance between airline evaluation values to the positive and negative ideal solution; At last calculating the grey correlation relative closeness. Through the case analysis, the feasibility and effectiveness of the method is illustrated.
\end{abstract}

\section{Introduction}

Air strikes have the characteristics of sudden strong, accurate strike, long distance and so on. It is a common method of modern war. But as the development of the air defense system, the radar and the air defense missile are the great threat to the aircraft. In order to respond to the threat of air defense, the aircraft in the technology has also been developed, such as stealth, speed, intelligent planning and other techniques. The COA(course of action) produced by mission planning system is becoming more and more accurate, close to the actual scene. The attack airline in COA, which is based on the simulation of radar detecting and the shooting of air defense missile, is generated according to real 3D terrain. In recent years, there are a lot of methods for automatic generation of 3D flight routes, such as in literature[1-3]. Now the problem is how to evaluate airlines based on operational requirements of commander.

General civil airline evaluation refers to airline safety, comfort, economy and so on, to provide technical reference for final decision on choice. The military ground-attack airline is considered in the evaluation of combat effectiveness, the threat level of missile, the possibility of detection, flight time, airline length, fuel consumption and easy to fly. Therefore, in essence, the course of evaluation is a multi-objective decision problem, only a qualitative or quantitative analysis means alone is difficult to find the "best solution". In recent years, the application of multi-objective theory and method has larger development. Among them, the literature[4-9] respectively adopted the entropy theory combined with grey correlation analysis method, D-S evidence reasoning, set pair analysis theory, combined the analytic hierarchy process(AHP) and grey evaluation method, AHP and triangle fuzzy number, grey relation projection method and based on the ideal point decision methods of combination, uncertainty and ambiguity problem of processing information, sorting and optimization scheme. Although researchers have made great progress in study of algorithm, but a lot of problems exist in the practice, such as evaluating according to some special requirements. Therefore, on the basis of literature[10], this paper uses the fuzzy theory and grey theory to extend TOPSIS, in addition to solve the problems of the information uncertainty and ambiguity, also manifests the intention of commander's. The experimental results show that the method, can meet the requirements of the commander, improve the efficiency of operational decisions.

\section{Evaluation Model}

There are seven indexes to evaluate the attack airline, combat effectiveness, the threat level of 
missile, the possibility of detection, flight time, airline length, fuel consumption and easy to fly.

(1) The effect of the attack by the weapons and ammunition from the attack plane[11];

$\mathrm{E}=\mathrm{e}^{-\alpha \mathrm{t}}\left[1-\mathrm{e}^{-\beta \mathrm{t}}\right]$

$\alpha=\lambda \mathrm{p}_{1}, \beta=\mathrm{up}_{2}$

$E$ is task completion rate, $t$ is time, $\lambda$ is the number of threats, $p_{1}$ is the probability of the plane destroyed by treat at once time, $u$ is the average time for flying to attack targets, $p_{2}$ is the probability of target was destroyed by once attack.

(2) The probability of threat probability during the flight time was hit by anti-aircraft missiles[12];

$\mathrm{S}(\mathrm{A})=\mathrm{P}_{\left(\mathrm{t}>\mathrm{t}_{\mathrm{fm}}+\mathrm{t}_{\mathrm{rm}}\right)}=\int_{\mathrm{t}_{\mathrm{fm}}+\mathrm{t}_{\mathrm{rm}}}^{\infty} \lambda_{1} \mathrm{e}^{-\lambda_{1} \mathrm{t}} \mathrm{dt}$

$\mathrm{S}(\mathrm{A})$ is the probability of plane killed by missile, $\mathrm{t}_{\mathrm{fm}}$ is the time for air defense missile to intercept point, $t_{r m}$ is the reaction time of air defense missile, $\lambda_{1}$ is the density of air strike at the time of air defense missile intercept.

(3) The probability of detection by radar during the flight time[13].

$\mathrm{R}_{\max }=\left[\frac{\mathrm{P}_{\mathrm{T}} \mathrm{G}^{2} \lambda^{2} \sigma}{(4 \pi)^{3} \mathrm{kT}_{0} \mathrm{~B}_{\mathrm{n}} \mathrm{F}_{\mathrm{n}}\left[\frac{\mathrm{S}}{\mathrm{N}}\right]_{\min } \mathrm{L}}\right]^{\frac{1}{4}}$

$P_{T}$ is radar transmit pulse power, $G$ is radar antenna gain, $\lambda$ is the wavelength of radar, $\sigma$ is RCS, $\mathrm{k}$ is the constant of Pohl Seidman, $T_{0}$ is working noise temperature, $B_{n}$ is noise bandwidth, $\mathrm{F}_{\mathrm{n}}$ is noise figure, $(\mathrm{S} / \mathrm{N})_{\min }$ is the minimum signal to noise ratio required for the detection of the input end of the detector, $\mathrm{L}$ is total loss coefficient.

If the electromagnetic jamming is considered, the radar detection range is calculated.

$\mathrm{R}_{\mathrm{t}}=\left[\frac{\mathrm{P}_{\mathrm{t}} \mathrm{G}_{\mathrm{t}}^{2} \sigma \mathrm{K}_{\mathrm{r}}}{4 \pi \mathrm{B}_{\mathrm{r}} \frac{\mathrm{S}}{\mathrm{J}} \mathrm{L}_{\mathrm{r}}} \sum_{\mathrm{j}=1}^{\mathrm{n}} \frac{\mathrm{R}_{\mathrm{j}}^{2} \mathrm{~B}_{\mathrm{j}} \mathrm{L}_{\mathrm{j}}}{\mathrm{P}_{\mathrm{j}} \mathrm{G}_{\mathrm{j}}(\theta) \mathrm{G}_{\mathrm{r}}(\varphi) \gamma_{\mathrm{j}}}\right]^{\frac{1}{4}}$

$\mathrm{K}_{\mathrm{r}}$ is the factor of radar anti-jamming, $(\mathrm{S} / \mathrm{J})$ is $\mathrm{SIR}, \mathrm{R}_{\mathrm{j}}$ is the distance between the jamming and the radar, $L_{j}$ is system loss of the jamming machine, $\gamma_{j}$ is the polarization loss of interference signals on the radar antenna, $G_{j}(\theta)$ is the gain of the jamming machine in the radar direction, $\mathrm{G}_{\mathrm{r}}(\varphi)$ is the gain of radar antenna in the direction of the interference machine. $\theta$ is the interfering direction and the angle between the interference of the machine and the radar line, $\varphi$ is the angle between the main lobe of radar and the connection between radar and jamming machine. The relationship between radar detection probability and distance is:

$$
\mathrm{P}=\frac{\mathrm{R}^{4}}{\mathrm{r}^{4}+\mathrm{R}^{4}}
$$

$\mathrm{P}$ is radar detection probability, $\mathrm{R}$ is radar detection range, $\mathrm{r}$ is the distance between target and radar.

(4) The time duration of the flight;

(5) the length of the airline;

(6) The fuel consumed during the flight [14];

$\mathrm{W}=\mathrm{w}_{1} \mathrm{t}_{1}+\mathrm{w}_{2} \mathrm{t}_{2}+\mathrm{w}_{3} \mathrm{t}_{3}+\mathrm{w}_{4} \mathrm{t}_{4}$

There are great differences in the characteristics of different flight phases of flight aircraft, fuel consumption characteristics are not the same. The flight stage is divided into 4 stages: sliding, climb, cruise and fall. The fuel consumption in each stage is obtained by stage of flight time multiplying the average consumption.

(7) The difficulty of airline flight control, such as low-altitude flying, the difficulty is high value, high-altitude flying, the value is not high.

The evaluation methods of airline is: 1) The airline requirements for airline was converted to the normalized triangular fuzzy number of weights; 2) Standardized the indexes of airline evaluation, then according to normalized weights, assembled the fuzzy weights; 3) used the gray correlation to measure the degree of positive and negative ideal solution close to the current airline, with extended TOPSIS method. 4) Finally, according to the close degree of each airline to sort, then got the best airline. 


\section{The Example Analysis}

Assuming that the air force command post accept the task to attack enemy radar station. Through situation analysis and airline planning system developed 4 airlines. The specific evaluation process is as follows:

(1) Determine the fuzzy weights of evaluation indexes, the table 1 is the three advices to index of evaluation. And then converted into triangular fuzzy Numbers, as shown in table 3.

Tab.1 Evaluation Weight Table

\begin{tabular}{cccc}
\hline The evaluation index & Advice 1 & Advice 2 & Advice 3 \\
\hline combat effectiveness & more important & important & more important \\
the threat level of missile & important & important & very important \\
the possibility of detection & no important & no important & more important \\
flight time & more important & More important & no important \\
airline length & more important & More important & more important \\
fuel consumption & little important & little important & no important \\
easy to fly & more important & no important & more important \\
\hline
\end{tabular}

(2) Through the simulation system to evaluate airline, evaluation data of decision matrix (table 2), after standard data processing here are standardized decision-making matrix A:

Tab.2 Evaluation Parameters

\begin{tabular}{ccccc}
\hline The evaluation index & airline 1 & airline 2 & airline 3 & airline 4 \\
\hline combat effectiveness & 0.3 & 0.8 & 0.7 & 0.9 \\
the threat level of missile & 0.7 & 0.9 & 0.8 & 0.8 \\
the possibility of detection & 50 & 500 & 600 & 700 \\
flight time & 6 & 10 & 2 & 2 \\
airline length & 20 & 50 & 15 & 17 \\
fuel consumption & 3 & 30 & 20 & 24 \\
easy to fly & 4 & 20 & 30 & 40 \\
\hline
\end{tabular}

(3) Calculating relative solution of fuzzy grey correlation degree and degree of grey incidence is relatively close to, as shown in table 3 .

Tab.3 Close degree Sort Table 1

\begin{tabular}{ccc}
\hline airline & Fuzzy closeness & Close degree \\
\hline airline 1 & $(0.4870,0.5009,0.5102)$ & 0.4993 \\
airline 2 & $(0.5403,0.5339,0.5311)$ & 0.5351 \\
airline 3 & $(0.5072,0.5037,0.5025)$ & 0.5045 \\
airline 4 & $(0.4801,0.4698,0.4622)$ & 0.4706 \\
\hline
\end{tabular}

Calculation results as shown in table 6, according to the close degree of grey relation , the order of the four schemes is: airline $2>$ airline $3>$ airline $1>$ airline 4 . From the weight of evaluation index table (table 2) can be seen in: " the threat level of missile " and " combat effectiveness " weight is bigger, the calculation results accord with expert preferences.

If the combat mission has strict limits to the time, you can modify the table 2 " fuel consumption " in the three experts as "very important". After a recount of the fuzzy grey correlation degree and grey correlation degree as shown in table 7 . The order changes accordingly, airline $1>$ airline $2>$ airline 3 > airline 4 . Can be seen from table 4, airline 1 "fuel consumption" is the smallest. 
Tab.4 Close Degree Sort Table 2

\begin{tabular}{ccc}
\hline airline & Fuzzy closeness & $\begin{array}{c}\text { Close } \\
\text { degree }\end{array}$ \\
\hline airline 1 & $(0.5116,0.5144,0.5182)$ & 0.5147 \\
airline 2 & $(0.5048,0.5097,0.5153)$ & 0.5099 \\
airline 3 & $(0.4975,0.4983,0.4992)$ & 0.4983 \\
airline 4 & $(0.4855,0.4775,0.4684)$ & 0.4771 \\
\hline
\end{tabular}

\section{Conclusion}

By integrating fuzzy theory and grey system theory and method of multi-objective decision-making theory effectively solve the fuzziness and uncertainty of combat command decision making problems. Through examples proved that this method is validity and feasibility, can shorten the decision-making time, improve the efficiency of command.

\section{References}

[1] Chai Yizhe, Yang Rennong,Ma Mingjie, et al. Research of Air Route Planning Optimization Method without Threat Based on Improved Ant Colony Algorithm. Journal of Air Force Engineering University. Natural Science Edition. 2015. 16(4): 9 12.

[2] Qiu Xiaohong, Zhang Linchagn, Gao Jinyuan. Fast Generation Algorithm For Horizontal Trajectory of Tactical Flight Mission. Journal of Beijing University of Aeronautics and Astronautics, 1996.122(16): 775 779.

[3] Li C. H., Zheng C. W.,Zhou C. P., et al. Fast search algorithm for 3D-route planning. Journal of Astronautics. 2002. 23(3): 13 17.

[4] Tong H P, et al. The Model of Selecting Naval Base Antiaircraft Battle Scheme Based on the Analysis Of Grey Relevancy and Entropy Weight [J]. Fire Control\& Command Control, 2012, 37(1): 113 115

[5] Chen X Y, Gong M S, Jing Y W, Selection of Operation Schemes with Incomplete Information Based on D-S Evidence Theory[J]. Journal of Northeastern University(Natural Science), 2012, 33(8): 1069 1073

[6] Chen Xiangyong, Jing Yuanwei. Selection of operation schemes based on set pair analysis. Journal of Northeastern University(Natural Science), 2011, 32(8): 1068 1072 .

[7] Tan L Z, et al. Application of Grey AHP in Optimization Plane of Naval Ships Air Defense Combat[J], Ordnance Industry Automation, 2010, 29(1): 40 44

[8] Cao J, et al. TFN-AHP Model for Performance Evaluation of Missile Systems[J], ACTA ARMAMENTARII, 2005, 26(4), 566 569

[9] Zhao S Z, Scheme Selection of Aircraft Top-layer Design Based on Multi-criteria Decision-making Approach[J], Flight Dynamics, 2012, 30(1): 29 33

[10] ZHANG Y, et al. Effectiveness evaluation of Early-warning aircraft based on hierarchy TOPSIS[J], Systems Engineering and Electronics, 2011, 33(5): 1051 1054

[11] Huang Jun, Wu Zhe. Assessments of Air-to-Surface Target Attacking Effectiveness for a Combat Aircraft[J]. Acta Aeronautica et Astronautica Sinica. 1999. (01): 70 72.

[12]Han Xing, Duan Fangfang, Gao Jian. Research on Firing Probability of Air Defense System [J]. Fire control Radar Technology. 2014. (03): 26 28. 
[13]Qiu ZhiPing, Lu QiangHua. Interval Estimation for Radar Detection Range[J]. Aircraft Design. 2008. (02): 1 5.

[14]He YunCheng, Liu Kun, Shen XiaoYun, Zhou Bo. Simulation Study of Aircraft fuel consumption Estimates Model[J]. Computer Simulation. 2015. (05): 33 36. 